\title{
Psychosocial Problems among Children in Difficult Circumstances
}

K Sekar* and Kavitha P†

Abstract

Childhood is the most important phase in a person's life. The conducive environment available during this stage of life determines positive psychosocial development of an individual. The current study was conducted among 338 children in difficult circumstances to assess the stress, behaviour problem, adjustment in the areas of home, school, teachers, general and peers and self esteem. The results of the study brought out that, children in difficult circumstances undergo moderate to high stress. These children also exhibited higher behaviour problems which is antisocial and neurotic in nature. The adjustment is poor, especially, in the areas of general adjustment, teacher and school. The self esteem is also found to be average to poor. The results highlight the need for psychosocial interventions which are curative, preventive and promotive in nature to address the problems experienced by the children.

Keywords: Children in difficult circumstances, Psychosocial care, Behaviour problem, Adjustment, Self-esteem

" Professor and Head, Department of Psychiatric Social Work, NIMHANS, Bangalore, India; sekarkasi@gmail.com

† Project coordinator, NIMHANS- Every Child project on Enriching Psychosocial Competencies among Children by NGO's in South India, Bangalore, India; kavimanoj@gmail.com 


\section{Introduction}

Childhood is the formative period in a person's life. Hence it is important that the child grows up in a good environment that ensures safety, food, shelter, education, care and protection-a conducive environment that promises growth and development. Non availability of such conducive atmosphere is a threat to the growth and development of children. Child feels threatened and insecure in non conducive environments that may eventually manifest as a psychosocial problem wherein the child reacts to such situations in unacceptable ways. The child may appear to be sad and isolate itself from friends and peers, or easily get agitated or irritated and pick up fights with friends or argue for trivial reasons. Such children tend to become anxious about anything and appear fearful. Unable to accept and get along with these difficulties, children may run away and end up on the streets or in much threatening situations such as in antisocial gangs. Exposed to non conducive environments at a very young age leads to poor health, and poor scholastic performances and their psychosocial development is affected. Contributing factors to such difficulties among children are varied such as poverty, class discriminations, corruption, epidemics, disasters, etc. The cultural practices and beliefs of the community, social, geographic and political conditions of a country also influence this condition and inversely affect each child. Various socio-economic and cultural practices challenge their normal psychosocial development and interfere with their day-to-day activities.

\section{Review of literature}

UNESCAP (2008) defines "Children in especially difficult circumstances are those children who are for shorter or longer periods in their lives, exposed to intense multiple risks to their physical and mental health. A common characteristic of these children is that they lack proper adult care and protection and that they lead their lives outside mainstream society". Consolidation of various reports by (Mock \& de Buhr, 2009) reported that difficult circumstances among children represents a wide area and described differently by different organisations working with 
children. The causes for difficulty can be multiple and not poverty alone. Various difficulties reported identified in the report are working in exploitative situations, living away from biological parents or living with adopted families, survivors of armed conflict, sexual abuse/exploitation, trafficking and child labour. Problems such as HIV/AIDS further increase the magnitude of the problem globally. The factors that increase the vulnerability among children as reported by Skinner et al., (2006) are parental illness, poverty, unavailability of services, lack of basic needs such as clothing, food, crowded place of stay, inadequate care taking as well as specific child related issues such as disability, physical and sexual abuses, illness etc.

\section{Children in difficult Circumstances}

Globally, millions of children are affected due to urbanization that leads to increase in the number of street children worldwide, especially, in African countries. Across the world, 317 million children between the age group 5 and 17 years were into child labour as on 2004. Children involved in hazardous work were estimated to be 126 million and 217 million in other forms of child labour (Hagemann et al., 2006). As per UNICEF report of 2005, 5.7 million children were forced into bonded labour, 1.2 million children were trafficked per year and 8 million children were pushed into sex trade.

The Region of South Asia continues to be challenging for children with poverty and inequality, rising food prices and economic crisis, political insecurity, environmental degradation and recurrent natural disasters. Undernourishment, stunted growth, deprivation of schooling/education, high girl dropout rates, mortality and illhealth due to diarrhoea, acute respiratory infections, vaccinepreventable diseases and malnutrition is high in this area. (SAARC \& UNICEF, 2001-2010). In south Asia alone, 21.6 million children work. They are smuggled, trafficked across borders (ILO, 2004).

India has the highest child population with $38 \%$ of its population being children below the age of 14 years. Among children of the age group 6 to 14 years, less than $50 \%$ go to school and illiteracy among the girls of age group- 5 to 9 years, is reported to be $53 \%$. 
Compared to 16 out of every 1000 urban children, rural children reported more challenges in mental and physical health (20 out of every 1000 children). Death due to gender discrimination is reported on every $6^{\text {th }}$ child, sexual abuse among girls below 4 years is reported on every $4^{\text {th }}$ child, every second child is a child bride and 17 million children work in India (CRY, 2012; Sekar et al., 2012; UNICEF 2012).

The review of various reports on children in difficult circumstances identifies that, "the difficult circumstances vary according to social, cultural, political and economic condition of a country".

\section{Psychosocial problems among children in difficult circumstances:}

Difficult circumstances is a very wide term encompassing various problems experienced by children and many categories of children are described differently by different organizations (Mock \& de Buhr, 2009). A study conducted by NIMHANS revealed 24 kinds of various difficult circumstances among children in the southern states of India (Sekar et al., 2012). A number of reasons can be attributed to the cause of difficult circumstances. The major difficult circumstances seen among children are due to poor family conditions, social problems, conflicts or socio-cultural factors. Difficulties children experience will have an impact on their physical, psychological and social health. The impact of difficulties on children also depends on the kind of difficulty they are experiencing.

Multifaceted problems are reported by children exposed to maltreatment and traumatic experiences such as abuse, neglect, witnessing domestic violence, war and ethnic cleansing that negatively affects their attachment with the caregiving system. This results in them losing their ability for self regulation and interpersonal relatedness. Lifelong problems are associated with children who experience trauma that extends from childhood through adolescence to adulthood (Cook et al., 2005).

Major problems reported by children in difficult circumstances involve violence, psychosocial trauma and social behavioural problems. Nightmares, sleep disturbances, not playing/mingling 
with friends, sadness, poor or lack of appetite and withdrawal among younger children and problems such as poor concentration, anxiety and depression, hopelessness and aggressive behaviour is seen among older counterparts and adolescents. Certain antisocial behaviours and distorted value systems such as stealing, lying and deception becomes necessary for some such children for survival. These children experience psychosocial problems such as frequent recall of negative/violent experiences, anxiety and fear of the future, frustration, anger, depression, loneliness, distrust, sense of fear of being rejected or neglect (UNICEF, 2003). Children from socio-economically disadvantaged families have reported higher risk toward developing childhood psychopathology, emotional and behavioural problems as well as internalising problems (Sawyer et al., (2001), Xue, Leventhal, Brooks-Gunn, \& Earls (2005). Higher behavioural problem is observed among boys of the age group-10 to 16 years who, reportedly, run away from home when confronted with an environment where antisocial problem was reported among higher proportion of children (Khurana, Sharma, Shivananda Jena, Saha, \& Ingle, 2004). National Survey of America (Brown, 2004) reported higher behaviour problems among children living with single mothers, without parents and step families. The problems are more among older children and boys and the children from poor families showed higher behavioural and emotional problems. Children in difficult circumstances often develop certain developmental disorders and emotional problems that manifest as learning difficulty further sidelining them in schools (Kavitha, Sekar, \& Raj, 2012).

\section{Adjustment and self esteem}

Zimmermann, Schütte, Taskinen, \& Köller, (2013) explain the interplay between externalising behaviour, self esteem and academic achievement among children. Student misbehaviour is a pervasive problem affecting academic achievement. Low self esteem and behaviour problems result in low achievement. Poor adjustment/conflicted relationship with teacher exacerbate aggressive behaviour. Low self-esteem predicted increases in externalizing symptoms. A study on the self esteem among the children on street by Joseph (2007) revealed higher self esteem 
among them as compared to school children. A study on children of alcoholic parents (Moolakatt \& George, 2012) brought out that $72 \%$ of the children of alcoholics had higher self esteem, $70 \%$ of the children of alcoholics opined to have better adjustment capacities with home and environment, $84 \%$ of the respondents have poor adjustments with the teachers, $64 \%$ of the respondents have poor adjustment at school, $58 \%$ of the children had poor adjustment with peers.

Studies show that children from lower economic status are ridiculed by their peers and they develop psychosocial maladjustment, loneliness, school-related fear, anxiety, avoidance, depression and lower self esteem (Hawker and Boulton (2000), (Reijntjes, Kamphuis, Prinzie, \& Telch, 2010). Amato (2005) explains family factors such as stressful circumstance at home, poverty, conflict between parents, violence, poor parenting, mental illness, substance abuse etc., affect child's adjustment.

India has the largest number of child population in the world. The data shows various difficulties experienced by children in India. A scientific understanding of psychosocial problems among these children is required to develop psychosocial intervention modules to work with children in difficult circumstances. Hence, the current study is aimed at identifying the psychosocial problems among children in difficult circumstances. The aim, when split to specificity, pointed:

- To identify the impact of difficult circumstances among affected children

- To identify the behaviour and emotional problems among children in difficult circumstances

- To identify the adjustment among children in difficult circumstances in the areas of school, teachers, home, general and among peers

- To identify the self esteem among children in difficult circumstances 


\section{Methodology:}

A descriptive study was conducted among 338 children of the age group of 5 to 17 years attending the child care activity centres (CCAC) run by 8 NGOs (6 in Karnataka and 2 in Tamil Nadu). Total number of children in the age group 6 to 18 years, attending the CCAC was 10,756 as per the register maintained in the NGOs of which 5017 were regular to the CCAC. Data was collected from 50 children from each NGO. Inclusion criteria were applied that the children should be regular to the centres, and should not be reported of having any mental subnormality. Simple random sampling method was used to select children from the registry maintained in the NGO. Data was collected from 350 children. Standardised scales used to collect information from children were Family schedule (ICMR, 1984), Impact of Event (Horowitz et.al., 1979), Child Behaviour Questionnaire (Rutter, 1967), Reporting Questionnaire for Children (WHO, 1980), Pre Adolescent Adjustment Scale (Pareek et. al., 1970) and Self Esteem Index (Mc Kinnon, 1981). Data was cleansed and 338 data was marked for final analysis.

\section{Results:}

Children living in certain pockets of the society termed as social epi-centres undergo various traumas in life such as poverty, abuse, discrimination, stigma and isolation that affect their psychosocial development. Children in difficult circumstances identified in current study largely belong to the social epi-centres where the risk factors so exist that their vulnerability towards developing psychosocial problems is increased. 


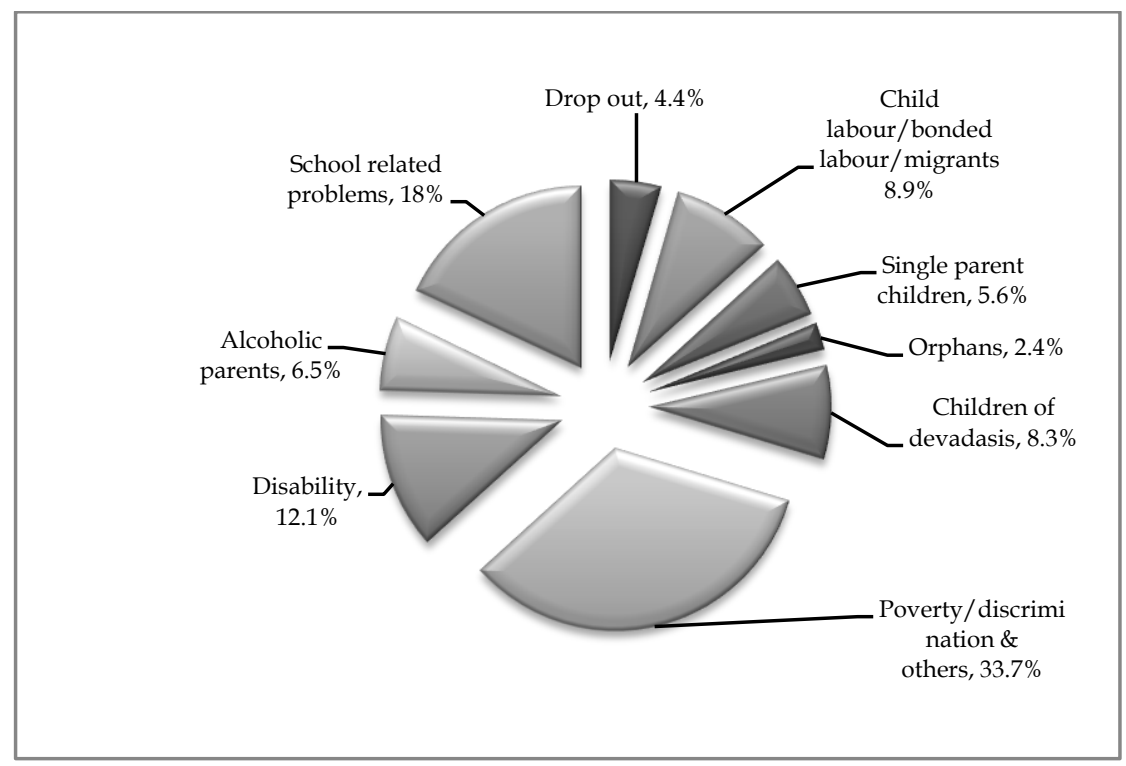

Fig 1. Socioeconomic background

The results of the study among 338 children showed that the problems reported by children are varied. The major problem reported by them was poverty and discrimination which was experienced by all the children though it was reported as primary problem by $33.7 \%$ of children. School-related problems such as inability to follow syllabus, punishments, lack of interest in studies etc., was reported by 4 out of every 10 children followed by disability at $12.1 \%$. The higher number of disabled children recorded is due to the data collected from the CCACs run by an NGO working exclusively for the disabled children through CBR approach. The study also identified children from families that has structural deficiencies such as being with a single parent due to death, separation, desertion, divorce, socio-cultural practice - the "Devadasi system" and orphanhood.

The socio demographic profile of children selected for the study showed that the mean age for children was $11.8 \pm 2.75$ years and the gender composition showed 59\% males, 59\% children were from joint families whereas $24 \%$ of them were living with a single parent. The mean years of education reported by these children were $6 \pm 2.4$ years. The mean family income was found to be Rs. $4820 \pm 3356$ ) 


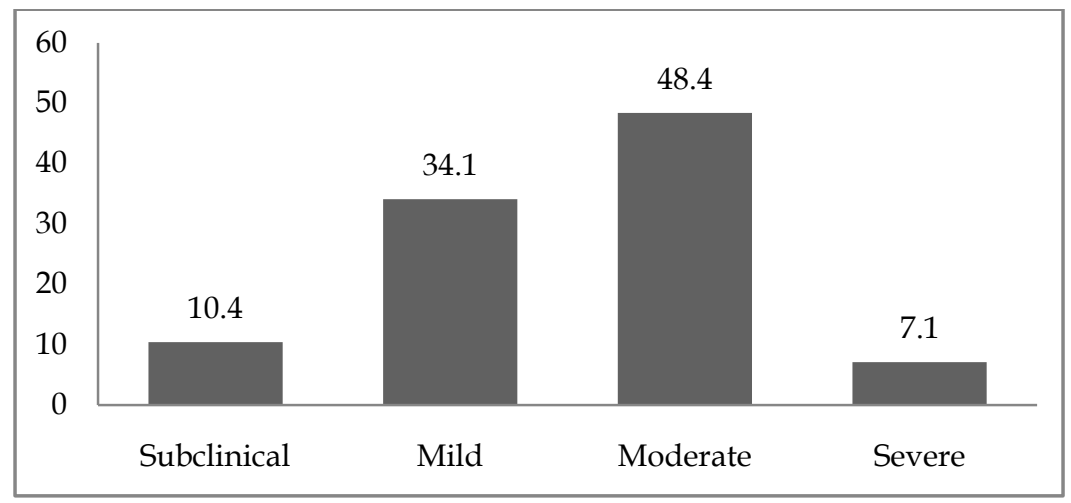

Fig 2. Impact of the event

The stress due to the impact of the difficult circumstances in life as reported by children brings out that $49 \%$ reported moderate stress and $7.1 \%$ reported severe stress. The mean for intrusion was $11.08_{ \pm} 7$, avoidance $13.75_{ \pm} 7.9$ and overall impact being $24.83_{ \pm} 12.9$. The result highlights that the children in difficult circumstances do experience moderate to severe stress due to difficulties in life. One way Anova test conducted showed that the stress due to impact of event is significantly higher among children experiencing poverty and other difficult circumstances (mean $=29.18, \mathrm{df}=8, \mathrm{P}<.001$ ). The stress experienced by children is high irrespective of their age. Pearson's correlation carried out brought out a significant negative correlation between income and stress $(\mathrm{P}<.01)$. The impact of stress is found to be significantly higher among males (mean= $\left.26.35_{ \pm} 11.52\right)$ as compared to females $(22.67 \pm 12.66, \mathrm{df}=1, \mathrm{p}<.01)$. 


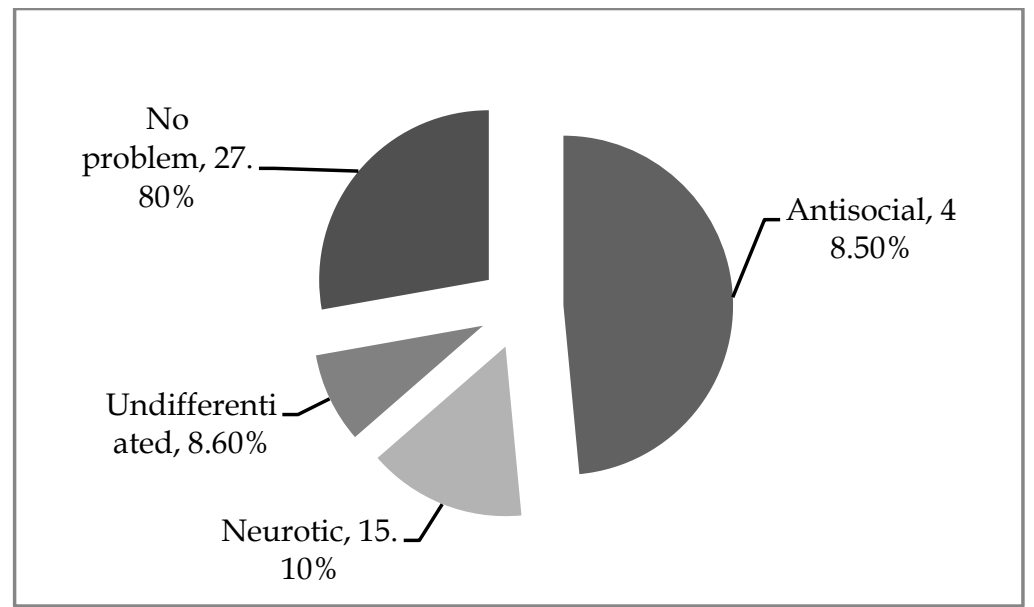

Fig 3. Behavioural problem

Teacher's reports on behavioural problem among children in difficult circumstances revealed antisocial behaviour among $48.5 \%$ and neurotic behaviour among $15.1 \%$ of children. The result shows that $72 \%$ of the children reported behavioural and emotional problems. Children living in nuclear families reported more problems. The Chi Square test conducted did not show any significant difference between the three types of families though there is a higher behaviour problem reported among the children from nuclear families. Behaviour problem is higher among children with school related issues (antisocial 80.3\%, neurotic $=31.8 \%$, undifferentiated $=3.3 \%$ ), disabilities (antisocial 43.9, neurotic $=24.4 \%$, undifferentiated $=9.8 \%$ ) as well as upbringing by Devadasis (antisocial $=35.7 \%$, neurotic $=7.1 \%$, undifferentiated $=3.6 \%$ ). The chi square test conducted revealed that the behaviour problem is significantly higher among children of alcoholics (antisocial behaviour 54.5\%, neurotic $8.2 \%$, undifferentiated $13.3 \%\left(X^{2}=39.78, \mathrm{df}=8, \mathrm{p}<0.01\right)$. It further revealed that the behaviour problem is higher among boys $(75.4 \%, \mathrm{n}=150)$ as compared to that of girls $(65.6 \%, \mathrm{n}=94)$ which is at significant level $\left(X^{2}=7.8, \mathrm{df}=3, \mathrm{p}<0.04\right)$. 


\section{Probable mental health problem behaviour}

The assessment among parents revealed that $85.5 \%$ of probable mental health problem behaviour is seen among children in difficult circumstances. The result confirms that behaviour problem is higher among children in difficult circumstances. Chi square test disclosed that the probable behaviour problem is significantly high among children living in nuclear families and children living with single parent $\left(\mathrm{X}^{2}=22.19, \mathrm{df}=2, \mathrm{p}<0.01\right)$ as well as among children of alcoholic parents where all children were reported with probable mental health problem behaviour $\left(X^{2}=30.91, \mathrm{df}=8, \mathrm{p}<0.01\right)$.

Table1 Adjustment in difficult circumstances

\begin{tabular}{|l|c|c|c|}
\hline \multicolumn{1}{|c|}{ Areas } & Positive $\%$ & Negative $\%$ & Neutral $\%$ \\
\hline Home & 64.8 & 35.2 & \\
\hline School & 32.2 & 38.8 & 29 \\
\hline General & 36.4 & 63.6 & \\
\hline Teacher & 27.2 & 45.3 & 27.5 \\
\hline Peer & 45.6 & 32.2 & 22.2 \\
\hline
\end{tabular}

The adjustment of children in difficult circumstances revealed that their adjustment in general is poor as $63.6 \%$ of them reported negative adjustment. Negative adjustment is also reported high with teacher as well as in school. Though adjustment at home shows a comparatively better figure, every $3^{\text {rd }}$ child in difficult circumstance reported negative adjustment at home. The data revealed poor adjustment among children in difficult circumstances in areas of home, school, general and teachers and with peers. The prominent negative adjustment is reported in the areas of school, general and with teachers. There is a significant negative correlation between adjustment at home and income. Higher the income lesser is the adjustment at home. 


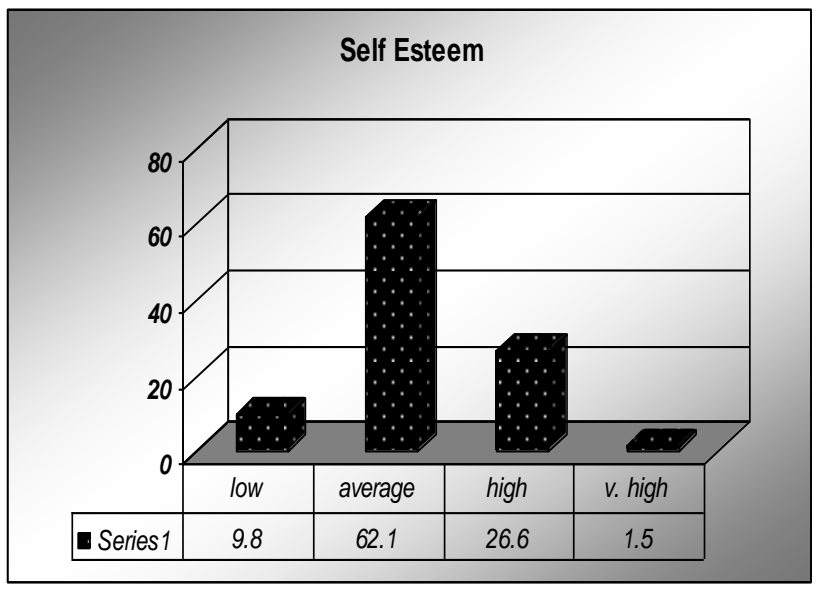

Fig4. Self esteem

The self esteem among the children in difficult circumstances shows that $62 \%$ of them reported average self esteem. The mean for the self esteem reported by children was $67.83 \pm 13.3$. The self esteem among the children in difficult circumstances is reported to be poor ranging between low to average. Chi square test carried out revealed that the self esteem is higher among children living in joint families as compared to children living with their single parents or children living with both parents. One way Anova conducted to find out the difference between family type and self esteem as well as gender and self esteem among children in difficult circumstances revealed that self esteem is significantly higher among the children living in joint families $(\mathrm{F}=18.96$, $\mathrm{df}=2 / 335, \mathrm{p}<0.00)$ and more among males $(\mathrm{F}=8.78, \mathrm{df}=1 / 336$, $\mathrm{p}<0.00)$ as compared to females. No correlation was observed between age and self esteem confirming that self esteem remains average among children in difficult circumstances irrespective of their age.

\section{Discussion:}

The results of the current study confirms that children in difficult circumstances form a wide group as difficulty faced by them differ 
according to the social, economic, and environmental factors. However, the study identified the problems to be grouped into 9 categories due to similar nature and lack of larger number of similar problems. These children have reported various difficulties such as exploitation, especially, in the case of child labour and bonded labour, unsafe environments at home, particularly reported more among children of alcoholics and Devadasis, stigma of lower socio-economic class among children from poor families. This confirms the fact reported by (Mock and de bur 2012) on the diversity of the issue and vulnerability among these children as explained by Skinner et al., 2006. The result of the current study identifies that difficulties experienced by children depends on the socio-economic and geographic specifications as well as family conditions which is in line with the literature that brings out various difficulties experienced by children globally (ILO 204, UNICEF, 2006), (SAARC \& UNICEF, 2001-2010). The difficulties among children identified in the current study brings out issues pertaining to poverty, class and caste discrimination, socio-cultural practices, difficulties at school and alcoholism in parents which commonly leads to similar repercussions for children across the world such as dropping out of school, child labour and health problems. Whereas trafficking, smuggling, commercial sexual exploitation, displacement among children are specific to the sociopolitical conditions of the country or the province.

The difficulties specific to the socio-economic and political conditions of a population in the current study is seen to affect children inversely. The results highlight the higher stress experienced by children due to poverty that leads to major problems such as child labour and dropping out of school. Illiteracy combined with exploitation and oppression by higher class further increases the stressors at home and in the community. Unsafe family and social environment where cultural practices such as Devadasi system exist adds to the existing trauma of children. A child living in such unfavourable conditions experiences higher stress irrespective of age that draws attention to the fact that children experience stressors constantly in their life. Higher stress among children in difficult circumstances is reported by Cook et al., (2005). UNICEF (2003) has reported higher intrusive behaviour among the children in difficult circumstances whereas 
the current study also brings out higher avoidance among children such as trying not to think, talk or remember the incidents, thinking if it was not real etc.

The high stress experienced by the children manifests as behaviour problems. Lack of parental care and supervision, higher responsibilities of work, unsafe and poor social environment and wrong role models contribute to the behaviour and emotional problems such as hyperactivity, truancy, isolation, irritability, school refusal, disobedience, poor concentration and attention and appearing fearful. The results of the study identifies these problems to be exhibited more by children from specific population such as children of Devadasis, children of alcoholics and children who reported higher problem at school. Children of Devadasis experience higher stress due to the stigma and unsafe home environment. Higher violence, poor health and higher financial crisis become challenges for children from alcoholic families. Children in difficult circumstances who experience adverse events in family and society show poor school performance that invites punishments which in turn, leads to truancy, school refusal etc. Hence the results confirm that poor family and school environment contributes to higher behaviour problems among children in difficult circumstances. Similar result is reported by Sawyer et al., (2001), Xue, Leventhal, Brooks-Gunn \& Earls (2005) , Khurana et al., (2004), Brown (2004) that children from lower socio-economic class, runaway children, children from married stepfamilies, singlemother families, or orphans, particularly boys show higher behavioural problem.

Children in difficult circumstances experience higher stress that leads to unacceptable behaviour in them. This invites unfavourable responses from parents, friends, teachers and significant others. Adding to this is the social stigma of discrimination due to caste and cultural practices, poverty, disability, single parent status etc., that lowers the self esteem among the children. The current study highlights the role of joint families in forming a greater support system for children which in turn, ascertains self esteem among children in difficult circumstances. That self esteem does not vary according to age confirms that it is only the difficult circumstances experienced by the children that constantly have an adverse affect 
on their self esteem. These factors lead to poor adjustment at home, with friends, in school and with teachers. Higher self esteem reported among street children according to Joseph (2007) and Moolakatt \& George (2012) do not concur with the results of the current study whereas the poor adjustment among children in various difficult circumstances reported by Hawker and Boulton (2000), Reijntjes et al., (2010), (Amato, 2005) corroborate with the poor adjustment reported in the current study.

\section{Conclusion:}

The study highlights the psychosocial problems faced by children in difficult circumstances. The challenges and difficulties they face in their daily life induces higher stress in them that ranges between moderate to high. The higher stress experienced by the children interferes with their day-to-day life and results in various behavioural problems that are mostly antisocial in nature, which is reported more among boys. Children who reported problems at school, disabled children, children of Devadasis, alcoholics, particularly boys reported more behaviour problems.

The stress and difficulties and various other psychosocial problems leads to poor self esteem and adjustment among children in difficult circumstances, especially, in the areas of general adjustment and with teachers. Children in difficult circumstances need to be supported through curative, preventive and promotive programmes to reduce the impact of trauma in life. The psychosocial problems identified among children in difficult circumstances was addressed though a 6-year research project that addressed the problems among children by building up community resources. In order to address the stress due to difficult circumstances, a curative programme was developed, standardised and implemented with children. Psychosocial care was provided for children through standardised mediums. This helped children to ventilate, understand and overcome the trauma due to difficulties in life. The preventive/life skills education programme was designed to build up skills among children and to equip them to deal with the daily challenges in life. The specific difficulties at school and study-related problems were addressed through a student enrichment programme that was designed to promote the 
educational standards of first generation learners and build interest in them to study. There is a need for a conducive family atmosphere for children to grow up as healthy individuals. The enriching family life programme aimed at strengthening family relations was held, addressing issues at family level thereby promoting better family environment for children.

Children in difficult circumstances experience problems that induce high stress in them constantly. Psychosocial care, which is a holistic service, needs to be incorporated with the existing services such as education system, or by building community resources which would ensure provision of psychosocial services to children.

\section{References:}

Amato, Paul R. (2005). The impact of family formation change on the cognitive, social, and emotional well-being of the next generation. The future of children, 15(2), 75-96.

Brown, Susan L. (2004). Family structure and child well-being: the significance of parental cohabitation. Journal of Marriage and Family, 66(2), 351-367.

Cook, Alexandra, Spinazzola, Joseph, Ford, Julian, Lanktree, Cheryl, Blaustein, Margaret, Cloitre, Marylene, Kold, Bessel van der. (2005). Complex trauma in children and adolescents. Psychiatric Annals, 35:5.

Hagemann,F., Diallo,Y., Etienne, A., \&Mehran,F.(2006). Global child labour trends 2000 to 2004: International Labour Office.

Hawker, David SJ, \& Boulton, Michael J. (2000). Twenty years' research on peer victimization and psychosocial maladjustment: a meta-analytic review of cross-sectional studies. Journal of child Psychology and Psychiatry, 41(4), 441-455.

ILO. (2004). Child Labour and response-Overview note South Asia.

Joseph, P.(2007). Self Esteem Among Street Children in Chennai City. Retrived 08/10/2013, from Articlesbase.com http://www.articlesbase.com/non-profit-organisationsarticles/self-esteem-among-street-children-in-chennai-city166923.html 
Kavitha.P, Sekar.K, \& Raj.W. (2012). Psychosocial Care for Children in Difficult Circumstances-A Community Based Approach. National Journal of Professional Social Work, 13(1-2), 28-41.

Mock, Nancy, \& de Buhr, Elke. (2009). Children in Difficult Circumstances Maternal and Child Health (pp. 479-496): Springer.

Moolakatt, C J, \& George, S. (2012). Adolescent Children of Alcoholics: Social Work Response. Global Academic Society Journal: Social Science Insight, 5(4), 12 - 18.

Reijntjes, Albert, Kamphuis, Jan H, Prinzie, Peter, \& Telch, Michael J. (2010). Peer victimization and internalizing problems in children: A meta-analysis of longitudinal studies. Child abuse $\mathcal{E}$ neglect, 34(4), 244-252.

S. Khurana, N. Sharma, Shivananda Jena, Saha, R., \& Ingle, G.K. (2004). Mental Health Status of Runaway Adolescents. Indian Journal of Pediatrics,, 71(5), 405-409].

SAARC, \& UNICEF. (2001-2010). Assessment of Progress in the SAARC Decade of the Rights of the Child

Sawyer, M.G.,Arney, F.M., Baghrust, P.A., Clark, J.J., Greatz, B.W., Kosky, R.J., Zubrick, S.R. (2001). The mental health of young people in Australia: Key findings from the child and adolescent component of the national survey of mental health and wellbeing. Australian and New Zealand Journal of Psychiatry, 35 (6), 806-814.

Sekar.k, Kavitha.p, Roncalli, T. Arul, Aravindraj, E., Kumar, Sanjeev, \& Babu, Sudhir. (2012). Psychosocial care for chidlren in difficult circumstances. Bangalore: NIMHANS.

Skinner, Donald, Tsheko, N, Mtero-Munyati, S, Segwabe, M, Chibatamoto, P, Mfecane, S, . . Chitiyo, G. (2006). Towards a definition of orphaned and vulnerable children. AIDS and Behavior, 10(6), 619-626.

UNICEF. (2003). Training Handbook on Psychosocial Counselling for Children in Especially Difficult Circumstances, A trainer's Guide. Kathmandu, Nepal.

UNICEF. (2005). The state of the worlds children 2006: Excluded and invisible: Unicef.

UNICEF. (2012). Child Marriage in India. An analysis of available data (2012). New Delhi 
Xue, Yange, Leventhal, Tama, Brooks-Gunn, Jeanne, \&Earls, Felton J. (2005). Neighborhood residence and mental health problems of 5 to 11 year olds. Archives of General Psychiatry, 62(5), 554563 